\title{
Spatio-temporal differentiation of sound environment in urban functional areas of China
}

\author{
WANG Fuhong ${ }^{1}$, LI Jie ${ }^{2}$ \\ ${ }^{1}$ Lanzhou University of Finance and Economics, China \\ ${ }^{2}$ Northwest Normal University, China
}

\begin{abstract}
Urban acoustic environment, especially noise pollution, is a product of rapid urban development and urban scale expansion. It is one of the urgent environment problems in current urban planning and governance. This study analyzes the spatiotemporal changes of acoustic environment in the functional areas of cities above prefectural level based on the geographical perspective in China. The results shows that the higher urban level is, the more active acoustic environment in the functional areas will be; otherwise, the quieter it will be. The spatial variation of the acoustic environment in the functional areas in the east is generally higher than in the west, and the coastal areas is higher than interior during day and night, which is generally consistent with the spatial distribution characteristics of China's social and economic development. The influence factors of urban acoustic environment are multiple, the development of urban social economy has a significant influence on urban acoustic environment, and the factors like environmental protection consciousness of residents, environmental governance level of the city have a significant influence on urban acoustic environment. Therefore, the governance measures of urban acoustic environment should be more diversified.
\end{abstract}

\section{INTRODUCTION}

Since the reform and opening up, China has experienced rapid economic growth and achieved large-scale urbanization $^{[1]}$. From 1978 to 2016, Chinese urbanization rate increased from $17.92 \%$ to $57.35 \%$ in 2016 , with an average annual growth rate of $1.04 \%$ [2, ${ }^{3]}$.Rapid economic growth has greatly enriched people's material life, but it has also created many city-centered environmental problems. Urban environmental problems are mainly caused by noise pollution, solid waste, water and air pollution, among which, acoustic environmental quality is the environmental problem that attracts the most attention and receives the most reports and complaints ${ }^{[4]}$. Noise is generally considered to have a negative impact on the quality of urban life, and long-term exposure to noise pollution seriously affects mental and physical health ${ }^{[5,6]}$. Urban acoustic environment, especially noise pollution, is a physical phenomenon, which is obviously different from air, water pollution and other environmental problems ${ }^{[7]}$. The generation of noise is characterized by randomness, regionalism and sensibility ${ }^{[8]}$, which makes the governance of acoustic environment become a difficult and complex environmental quality factor in urban environmental problems. Therefore, multi-scale understanding of the change about urban acoustic environment is not only help to understand the law of change, but also conducive to develop the governance measures and improve the quality of urban acoustic environment.

Sound occurs in a specific time point in a specific space, which has not only time property, but also significant space property ${ }^{[9]}$. From the initial study of sound, geography was less involved. However, factors such as sound production, transmission and crowd perception are closely related to its spatial environment, so the research of sound also has significant geographical research characteristics ${ }^{[10]}$. Saldanha ${ }^{[9]}$ believes that sound can be perceived through the medium to give special meaning to space and place from the perspective of geography. Since the 1990s, foreign geographers have conducted a large number of researches on residents' perception of regional space and other issues from the aspects of sound and hearing, made people to have a deeper understanding and cognition of the multiple effects of sound on local perception [11, 12]. Through the research about spatiotemporal changes of acoustic landscape in urban and rural intersecting zones, $\mathrm{Joo}^{[13]}$ et al. find that urbanization process not only changed the pattern of landscape, but also changed the characteristics of acoustic environment in the region. The research on acoustic environment started relatively late in China, and the field of acoustic environment research is relatively narrow. The research in this field mainly focuses on music geography, tourism geography, architecture, landscape architecture and design at present in China ${ }^{[14,18]}$ with the integration and cross 
development of disciplines, it also provides new ideas and methods for the research of acoustic environment from the perspective of geography. In addition, city is an ecological environment system with great human interference, the widespread existence of sound sources and the high concentration of people make the urban acoustic environment become a hot topic of research, and most studies focus on noise monitoring and evaluation ${ }^{[19]}$, noise source control ${ }^{[20]}$. Small scale and single nature campus ${ }^{[21]}$, park ${ }^{[18]}$ and single city ${ }^{[7]}$ have become the hot spots in this filed. In conclusion, the sound environment research based on integration of subjects has achieved fruitful results. But there are some insufficient study of urban acoustic environment, mainly reflect in that the city sound environment is a complicated geographical phenomena, and the city of sound source, transmission and perception between the space environment are closely related, most research has focused on single city sound environment evaluation, the research about the relationship between the level of urban development and space environment, spatial characteristics of urban acoustic environment lack of attention, and more attention is paid to the research within a small scale.

Chinese urbanization has led to the rapid increase of urban population at present. Urban noise has become an urgent problem for urban development. Therefore, this paper analyzes the changes and spatial distribution characteristics of the acoustic environment in different functional areas of Chinese cities from the perspective of geographical research. Based on the noise monitoring data of the acoustic environment in the functional areas of prefecture-level cities in China, the paper focuses on the practical problem of urban acoustic environment, explores the internal changing rules of urban acoustic environment in order to provide reference for urban environmental governance.

\section{RESEARCH AREA AND RESEARCH METHOD}

\subsection{Research area and data source}

According to the acoustic environment quality standard issued by China in $2008^{[23]}$, urban acoustic environment is divided into five categories according to the functional characteristics and environmental quality requirements of urban areas (Tab.1). The monitoring of urban acoustic environment function areas is carried out quarterly every year, and the monitoring time of each city is relatively fixed In China. Chinese prefecture-level cities are taken as the research area, and the acoustic environment functional area data released by China environmental monitoring headquarters (http://www.cnemc.cn/) in 2015 and 2016 are used for analyzing the spatial and temporal characteristics of urban acoustic environment by statistical and spatial analysis in this study.

As an area where human and economic activities are highly concentrated ${ }^{[22]}$, the frequency of man-made sound produced in cities is far higher than that in other areas. In addition, different locations and environments produce different sounds scene, and their impacts on human health are also significantly different ${ }^{[10]}$. Based on the above, combining with the urban development level, refer to "the first, a new line of city institute of finance and economics" ranked cities above prefectural level in China ${ }^{[24]}$ on the basis of business resources, urban hub, urban population activity, lifestyle diversity and plasticity future five indicators released "2018 China's urban commercial charm list", it divide First-Tier cities, New First-Tier cities, Second-Tier cities, Third-Tier cities, Fourth-Tier cities or Fifth-Tier cities, then the spatiotemporal variation characteristics of acoustic environment in different urban functional areas are divided. In addition, due to the objectivity of data collection, there is a lack of the mean of equivalent sound levels between night and day in each city in the fourth quarter of each year, and there are few monitored urban data of class 0 and class $4 \mathrm{~b}$. Therefore, this paper only analyzes the changes of the acoustic environment of class $1-4$ a functional areas in the first three quarters of 2015-2016.

Tab.1 Monitoring division and noise limit of urban acoustic environment functional area

\begin{tabular}{|c|c|c|c|}
\hline \multirow{2}{*}{$\begin{array}{c}\text { Functional area category } \\
\text { Class } 0 \text { acoustic environment } \\
\text { functional area }\end{array}$} & \multirow{2}{*}{$\begin{array}{c}\text { meaning } \\
\text { Special quiet areas, such as convalescent areas }\end{array}$} & \multicolumn{2}{|c|}{ Noise limit value $(\mathrm{dB}(\mathrm{A}))$} \\
\hline & & $\begin{array}{c}\text { day } \\
\text { night }\end{array}$ & $\begin{array}{l}\leq 50 \\
\leq 40\end{array}$ \\
\hline \multirow{2}{*}{$\begin{array}{c}\text { Class } 1 \text { acoustic environment } \\
\text { functional area }\end{array}$} & \multirow{2}{*}{$\begin{array}{l}\text { Residential, medical and health care, cultural education, scientific } \\
\text { research design, administrative office as the main function, need to } \\
\text { keep quiet area. }\end{array}$} & day & $\leq 55$ \\
\hline & & night & $\leq 45$ \\
\hline \multirow{2}{*}{$\begin{array}{c}\text { Class } 2 \text { acoustic environment } \\
\text { functional area }\end{array}$} & \multirow{2}{*}{$\begin{array}{l}\text { Commercial finance, market trade as the main function, or } \\
\text { residential, commercial, industrial mixed, need to maintain } \\
\text { residential quiet areas. }\end{array}$} & day & $\leq 60$ \\
\hline & & night & $\leq 50$ \\
\hline \multirow{2}{*}{$\begin{array}{l}\text { Class } 3 \text { acoustic environment } \\
\text { functional area }\end{array}$} & \multirow{2}{*}{$\begin{array}{l}\text { Industrial production, storage and logistics as the main function, the } \\
\text { need to prevent industrial noise on the surrounding environment has a } \\
\text { serious impact }\end{array}$} & day & $\leq 65$ \\
\hline & & night & $\leq 55$ \\
\hline \multirow{4}{*}{$\begin{array}{c}\text { Class } 4 \text { acoustic environment } \\
\text { functional area }\end{array}$} & \multirow{4}{*}{$\begin{array}{l}\text { The areas that need to prevent traffic noise from seriously affecting } \\
\text { the surrounding environment within a certain distance on both sides } \\
\text { of the traffic trunk include category } 4 \mathrm{a} \text { and category } 4 \mathrm{~b} \text {. The } 4 \mathrm{a} \\
\text { category includes expressway, first-class highway, second-class } \\
\text { highway, urban expressway, urban trunk road, urban sub-trunk road, } \\
\text { urban rail transit (ground section), and areas on both sides of inland } \\
\text { water way. Class } 4 \mathrm{~b} \text { is the area on both sides of the main railway. }\end{array}$} & 4a day & $\leq 70$ \\
\hline & & 4a night & $\leq 55$ \\
\hline & & 4bday & $\leq 70$ \\
\hline & & 4b night & $\leq 60$ \\
\hline
\end{tabular}




\subsection{Spatial hot spot analysis}

Hot spot analysis is used to identify hot spots (high value) and (low value) with statistically significant features in spatial clustering features ${ }^{[25]}$. In this paper, getis-ord $G i^{*}$ in GIS was used for analysis to calculate the $Z$ score and $P$ value of each element in the data set, so as to determine the clustering positions of high and low values in the spatial pattern distribution of noise. The calculation formula is as follow ${ }^{[26]}$ :

$$
G_{i}^{*}=\frac{\sum_{j=1}^{n} W_{i, j}-\bar{X} \sum_{j=1}^{n} W_{i, j}}{\frac{\left[n \sum_{j=1}^{n} W_{i, j}^{2}-\left(\sum_{j=1}^{n} w_{i, j}\right)^{2}\right]}{n-1}}
$$

Where, $X_{j}$ is the mean of equivalent sound levels of city $j, W_{i, j}$ are the spatial weights defined by the criterion of spatial distance between city $i$ and city $j$. In addition:

$$
\begin{gathered}
\bar{X}=\frac{\sum_{j=1}^{n} X_{j}}{n} \\
\mathrm{~S}=\sqrt{\frac{\sum_{j=1}^{n} X_{j}^{2}}{n}-\left(\bar{X}^{2}\right)}
\end{gathered}
$$

Where, $G_{i}{ }^{*}$ is $Z$ value, and $Z$ value is positive and significant, indicating that the average of urban equivalent sound levels around city $i$ is relatively large, belonging to high-value spatial agglomeration, it is a hot zone. On the contrary, $Z$ value is negative, which significantly indicates that the average of equivalent sound levels of cities around city $i$ is relatively small, belonging to low-value spatial agglomeration, and it is a cold zone.

\subsection{Spatiotemporal evolution characteristics of acoustic environment in urban functional areas}

The requirements of the areas of urban living, medical treatment, education on acoustic environment are rigorous. By analyzing the changes of acoustic environment in a class 1 functional area from 2015 to 2016 (Fig. 1), it proves that the equivalent sound level of this functional area shows a decreasing trend, and the decreases of sound level with the decrease of city level. New first-Tier cities generally have higher equivalent sound levels, reflecting more active human activity in these cities. The equivalent sound level in the second and third quarters is higher than that in the first quarter, which is mainly due to the higher day and night temperature in the second and third quarters, and the more frequent outdoor human activities during the day and night. The two types of functional areas are both commercial and trading areas in the city, and the characteristics of equivalent sound level changing with the city level are more significant. The equivalent sound levels in both daylight and new first-Tier cities were higher than those in other types of cities (Fig. 2). According to Fig. $2 \mathrm{~d}, 2 \mathrm{e}$ and $2 \mathrm{f}$, the equivalent sound level of New First-Tier cities is the highest at night. In the process of urban development in China, First-Tier cities like "Beijing, Shanghai, Guangzhou and Shenzhen" and other New First-Tier cities have higher population and business concentration than other cities, and the frequency of man-made sound is higher.

\section{The analysis of the Result}

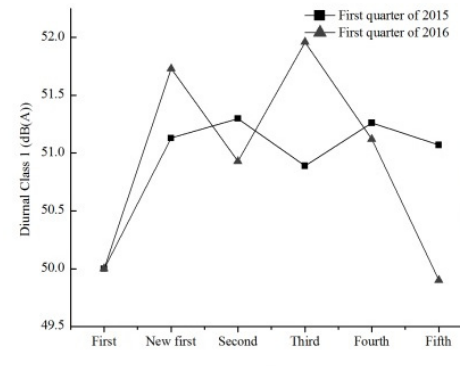

a
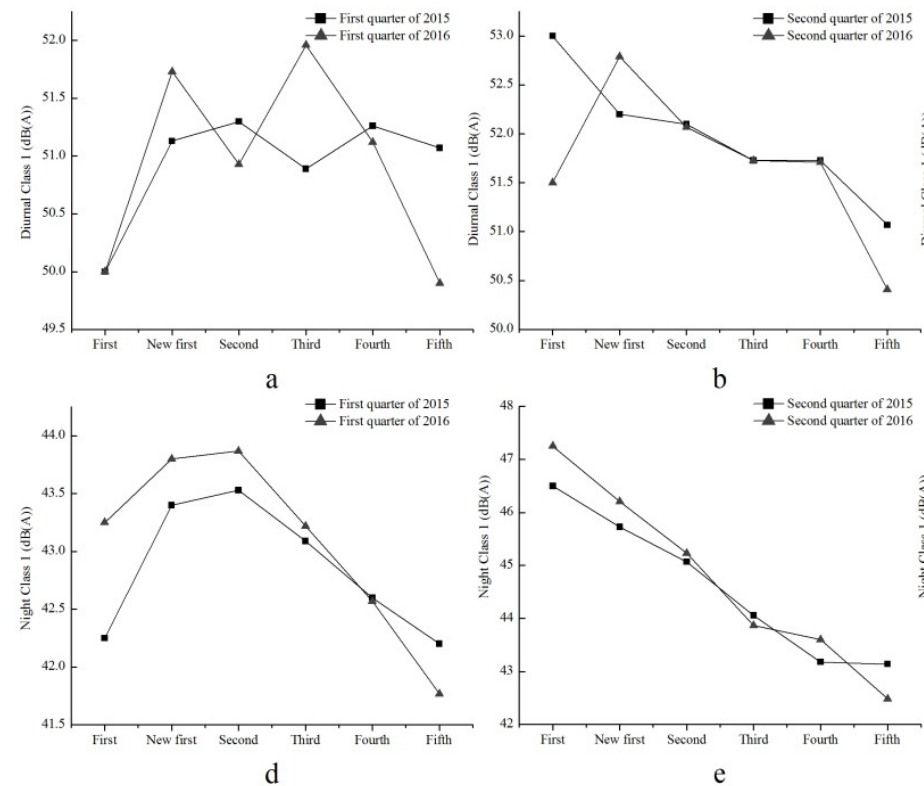

b
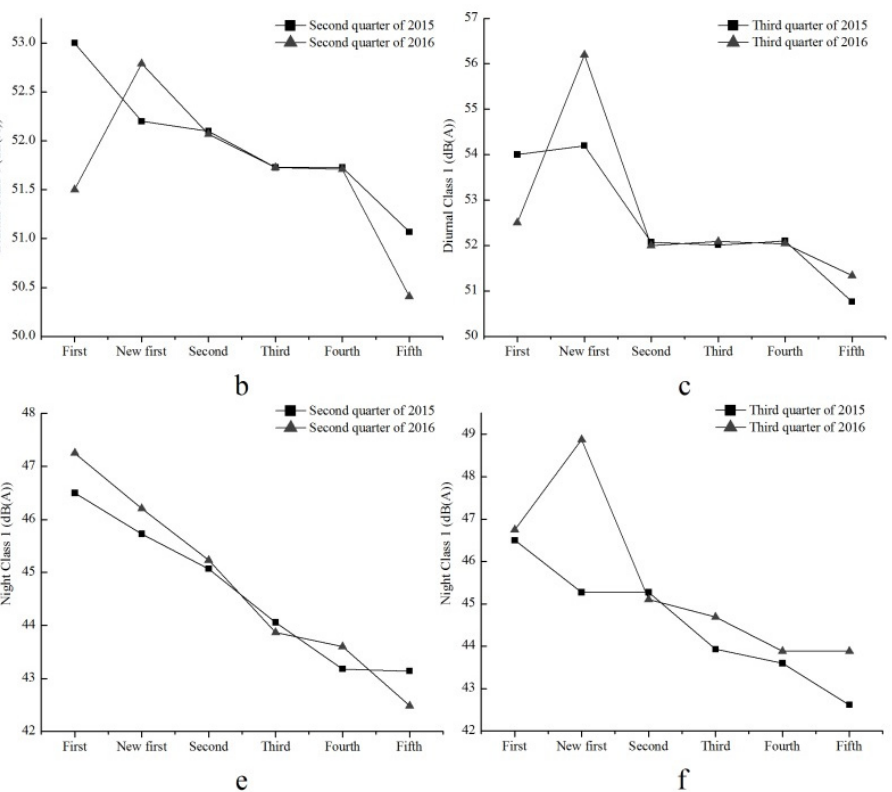

$\mathrm{c}$

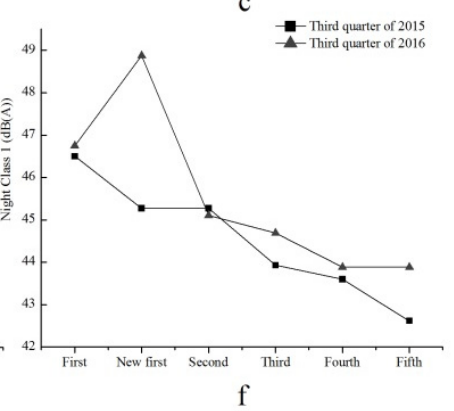

Fig.1 The average equivalent sound pressure level of category 1 urban functional area in 2015 and 2016 

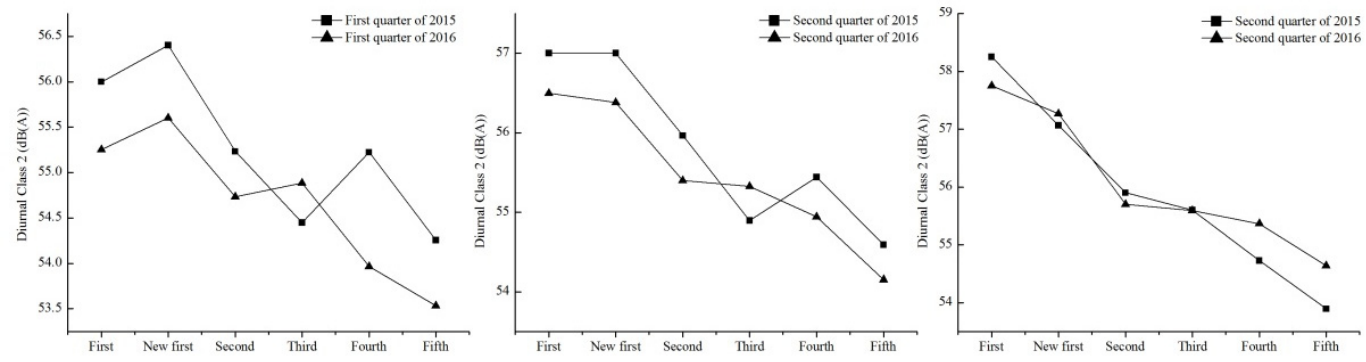

b
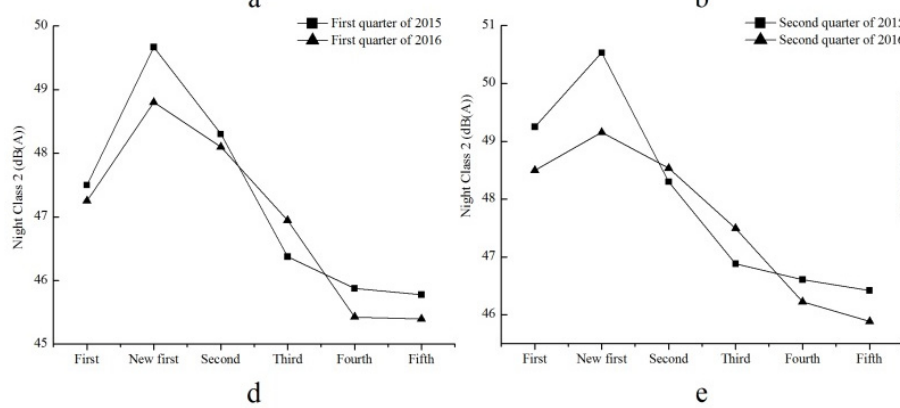

c

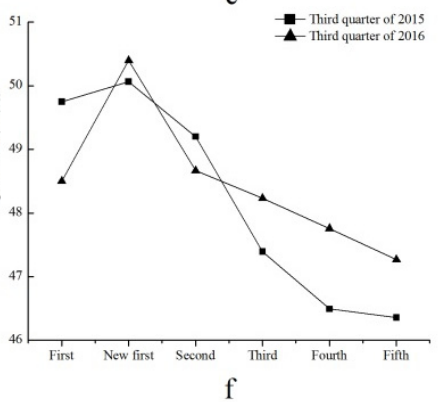

Fig.2 The average equivalent sound pressure level of category 2 urban functional area in 2015 and 2016

The three functional areas of the city are mainly industrial production areas. As can be seen from Fig. 3, the average equivalent sound level of New First-tier cities and Second-Tier cities is higher than other cities, reflecting that the former gathers more industrial production activities. The average of sound level in $4 \mathrm{a}$ functional area varies significantly with the level of city, it shows that there is a close relationship between urban traffic noise and urban scale. According to the acoustic environment monitoring of urban areas in China of 2016, traffic noise accounts for $10.6 \%$ of the noise category of urban areas. Compared with small cities, large cities gather more traffic flow, which leads to more serious traffic noise than small cities.
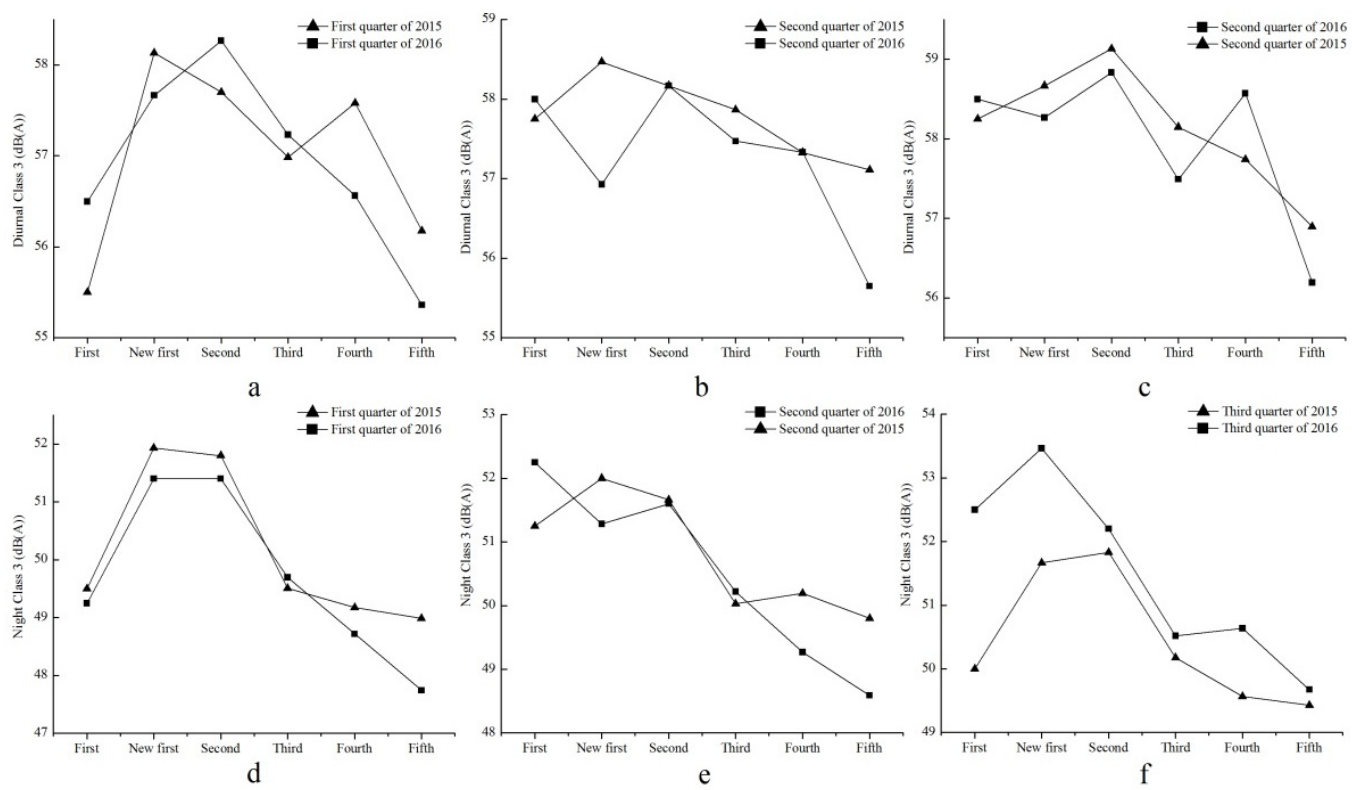

Fig.3 The average equivalent sound pressure level of category 3 urban functional area in 2015 and 2016 

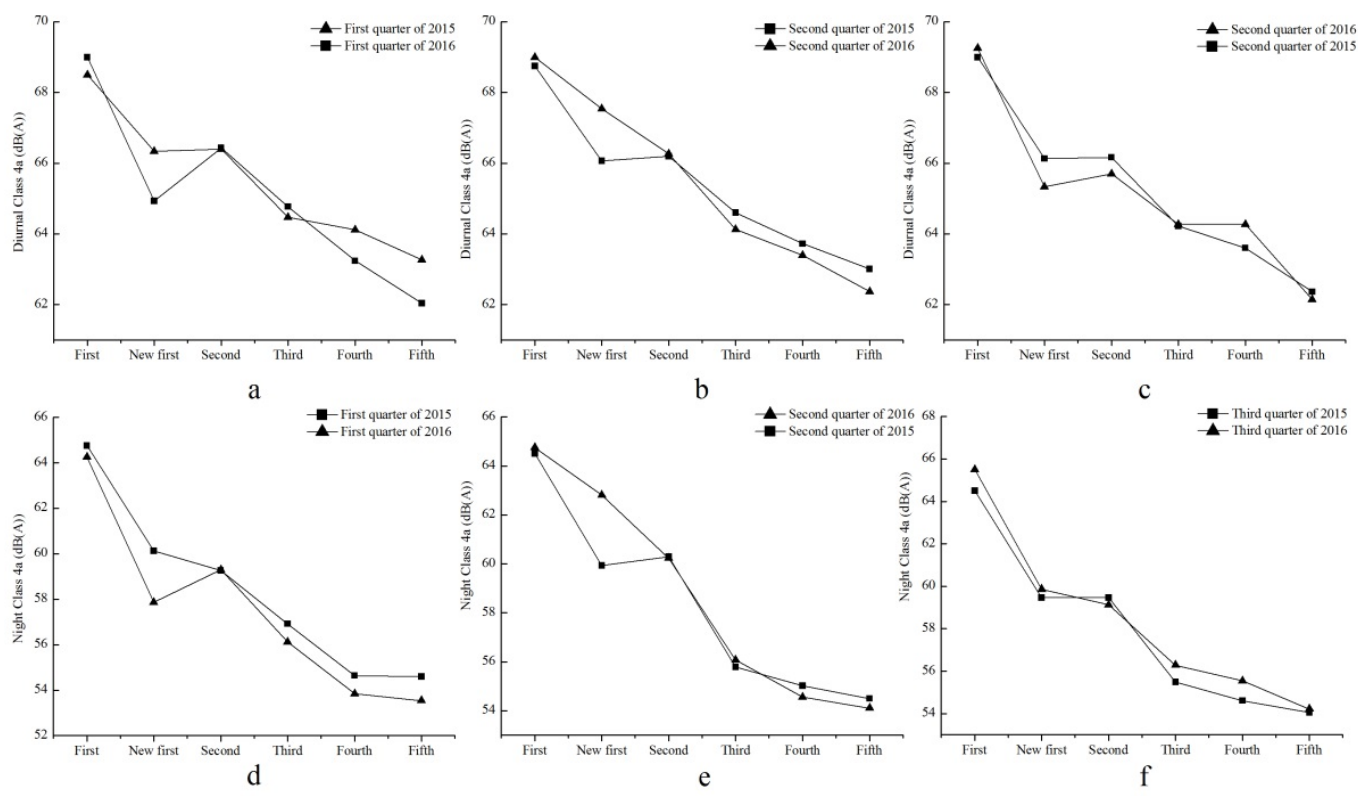

Fig.4 The average equivalent sound pressure level of category 4a urban functional area in 2015 and 2016

\subsection{The analysis of noise spatial agglomeration characteristics in urban functional areas}

Spatiality and Dynamics is the key features of sound scene, different types of sound scene present different characteristics in space-time ${ }^{[27,28]}$. As can be seen from Fig. 5, the spatial analysis characteristics of the first and second functional zones in Chinese cities are significant, shows that the eastern region is higher than the western
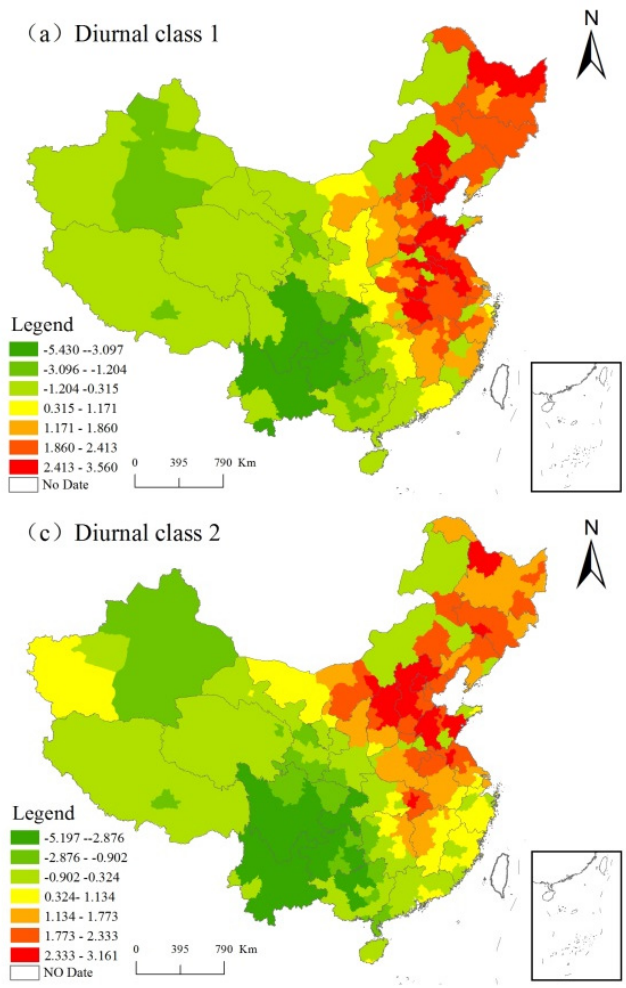

region and the coastal region is higher than the inland region. Cities in the eastern coastal areas have a higher level of development. A large number of cities with a higher level of development, such as Chinese First-Tier and New First-Tier cities, gather a large amount of population, medical care, education, business and other resources, leading to a higher probability of noise in such cities.
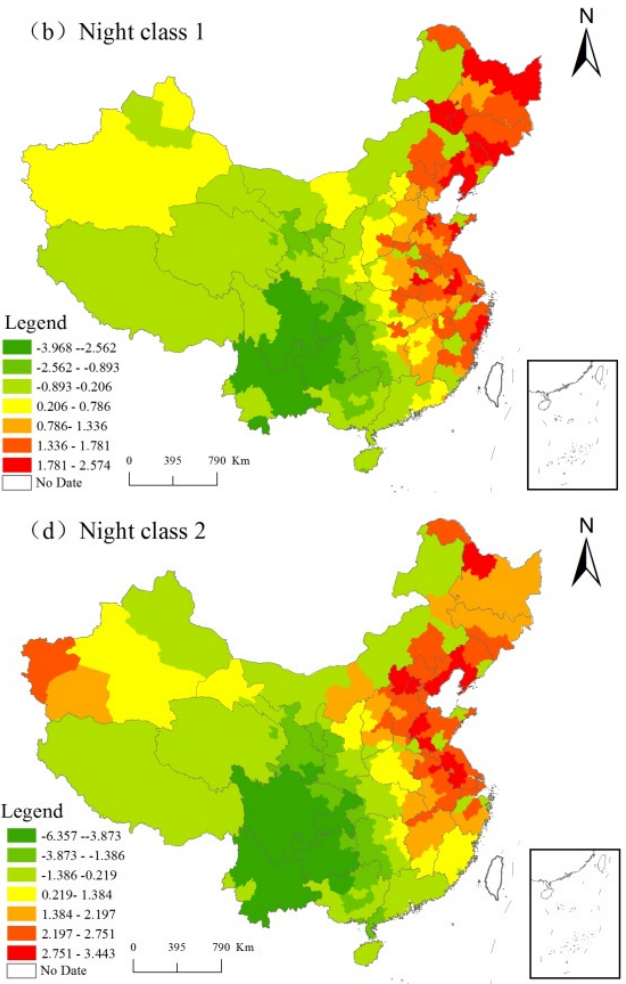

Fig.5 The spatial hotspot analysis of noise between day and night in urban functional areas of category 1 and 2

The spatial distribution of noise between day and night in the three types of urban functional areas is mainly concentrated in coastal, northeast cities of China
(Fig. 6a, 6b), especially the cities in northeast and southeast coastal areas are "busy" during the daytime, while the difference pattern is more obvious at night. 
Compared with coastal areas, cities in the central and western regions are "quiet". From the perspective about the space of the distribution of traffic noise, the northeast, coastal and middle or lower part of the Yangtze river areas of the city in the day time is higher,
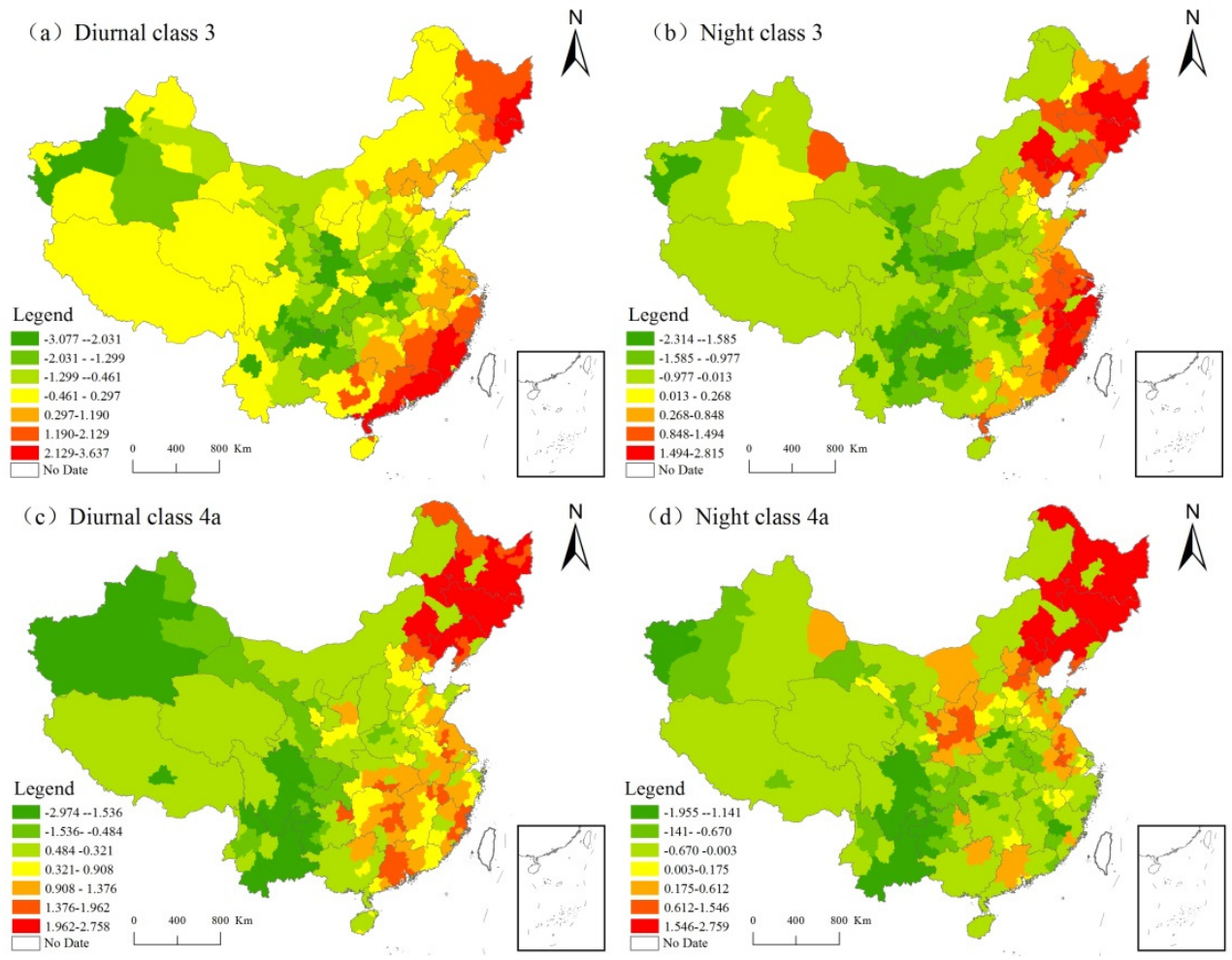
area is significantly higher than others.

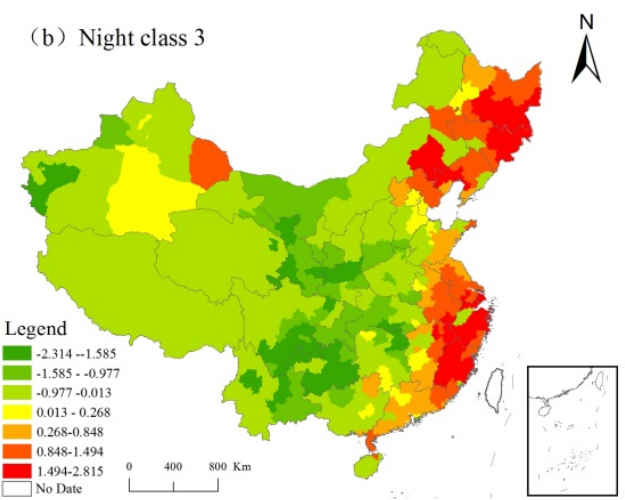

and at night the noise pollution in the northeast, coastal and Guanzhong areas is higher, traffic landscape in these areas reflects that the period of traffic flow in this

Fig.6 The spatial Hotspot analysis of noise between day and night in urban functional areas of category 3 and $4 \mathrm{a}$

\section{Discuss}

The relationship between man and earth is an important subject of geographical concern. As an important element of natural environment and man-made environment, sound has become an important factor and entry point to discuss the relationship between human, land and the change of human living environment ${ }^{[10]}$. The quality of urban acoustic environment directly affects the well-being of urban residents. However, urban residents, as the recipients of urban sound, will also have different health and well-being due to different environments, different living and working scenes or other factors. In addition, urban sound also witnesses the development and changes of cities, and use the acoustic environment of different stages of urban development to characterize and depict the characteristics of the development and changes of cities at different stages [29,30]. Therefore, it is of great significance to explore the spatiotemporal differences of different sounds in order to have a deep understanding about the interaction of sound production between natural and man-made environments, as well as to improve the individual, social and cultural significance of sound production and transmission.

The division of environmental functional areas is generally based on the governance of some existing environmental problems. As an important form of human habitation, cities gather in diverse elements such as population, means of production and transportation, thus contributing to the diversification of urban functions. It also forms functional areas dominated by different functions [31], which makes the acoustic environment of different functional areas in the city is different. According to the 2017 report on prevention and control of environmental noise pollution in China ${ }^{[32]}$ (Fig. 7), the compliance rate of acoustic environment in different functional areas of cities varies greatly, and the acoustic environment between day and night also varies significantly, the phenomenon reflects the difference of human activities in different time periods and functional areas of cities. In addition, although sound is a simple physical phenomenon, urban acoustic environment, especially noise, is closely related to urban population, number of motor vehicles, average traffic flow, environmental protection management measures and environmental awareness of urban residents ${ }^{[4]}$.As a reflection of the comprehensive strength of a city ${ }^{[33]}$, city level can best reflect the development level of these influential factors. The city classification adopted in this paper is based on big data and can truly reflect the development status of Chinese cities. From Fig. 1-4, it can be seen that the acoustic environment in each functional area of Chinese cities is closely related to the city level, and generally shows that with the decline of the city level, the acoustic environment in each functional area of cities becomes more "quiet". The significant difference of urban acoustic environment in time scale and space scale also 
reflects different levels of urban development and spatiotemporal distribution characteristics of cities. Therefore, it is more necessary to conduct long-term sound monitoring in different space and time periods in order to make policy adjustments to improve the sound environment quality of the region and improve the health and well-being of residents ${ }^{[34]}$.

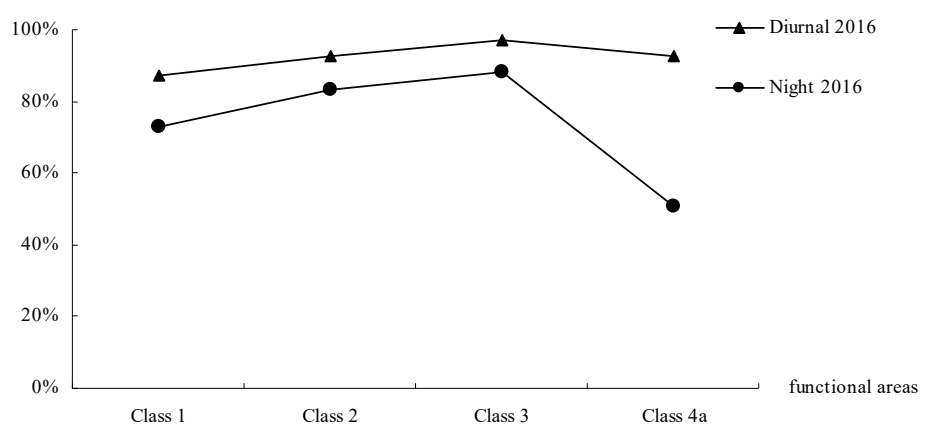

Fig.7 The sub-standard rate of sound environmental monitoring in urban functional areas in China in 2016

In addition to significant differences in time and space, urban sound also has obvious physical transmission and regional statistical characteristics ${ }^{[4]}$. Urban acoustic environment is the result of the comprehensive effect of various factors, and the hot spot in the system is relatively concentrated area of various factors ${ }^{[35]}$. Understanding the spatial distribution of acoustic environment is the basis of effective management of urban environment. In 2007, the European Union completed a noise map of noise sources based on airports, railways and road trunk lines, which provided a basis for further acoustic environmental governance by inquiring the noise in different areas of the city and the number of people who exposed to noise ${ }^{[32]}$. Therefore, it is of great significance to know the hot spots of urban acoustic environment accurately and grasp the changing rules of urban acoustic environment and carry out the systematic scientific management. From Fig. 5, Fig. 6 shows that the noise distribution between day and night hot areas are mainly distributed in the eastern coastal area, and it is similar to the spatial pattern of distribution of Chinese social and economic development, and both higher than coastal inland, it reflects that the aggregation of various factors in the process of urban social and economic development leads to a higher frequency and a wider range of noise, which has the most profound impact on the urban acoustic environment. However, the development of social economy is not the decisive factor that influences the acoustic environment of cities, but the governance level of urban environment and residents' awareness of environmental protection are the factors that affect the change of acoustic environment. As can be seen from Fig. 1, the average equivalent sound level of First-Tier cities in the first quarter was lower than the New First-Tier cities, reflects that some cities with higher grades were faced with more prominent environmental protection problems due to more dense population, which led to better supervision and governance of the urban environment. For example, Beijing, as a First-Tier city, has set up an automatic environmental noise detection system covering the whole city, established a sound noise management system and a mature departmental coordination mechanism, the city has formed effective measures to deal with various acoustic environmental noise problems.

Taking prefecture-level cities and cities above as examples, this paper analyzes the spatial and temporal distribution characteristics of urban acoustic environment in different functional areas in cities with different levels. Due to the objectivity of data collection and other factors, the research did not fully reflects the quarterly changes of urban acoustic environment throughout the year, and the results were limited to some extent. However, it could still reflect the changing characteristics of urban acoustic environment in China. It is helpful to comprehensively understand the urban acoustic environment problems faced by Chinese cities at the current stage, so as to provide reference for the acoustic environment management of regional cities. Therefore, it is necessary to further refine this research based on the perspective of geography in future studies, and explore the evolution rules and influencing factors of urban acoustic environment from different scales.

\section{Conclusion}

By comparing and analyzing the equivalent sound level mean of noise acoustic environment in cities with different levels and different functional areas of cities, it can be seen that the acoustic environment of cities with different levels is significantly different. Generally speaking, the acoustic environment in different functional areas of Chinese cities is closely related to the urban level. With the decline of the urban level, the acoustic environment in each functional area tends to be "quiet". From the perspective of the spatial distribution of noise in various functional areas of the city, the hot spots of urban noise distribution during day and night are generally consistent with the spatial distribution of Chinese social and economic development, the law is that the eastern region higher than the western region, the coastal region higher than the inland region. Urban acoustic environment pollution has the characteristics of strong randomness and wide distribution of sound sources. Social and economic development level is not the only factor influencing urban acoustic environment, 
but also closely related to the management measures of urban acoustic environment and the environmental awareness of urban residents.

\section{Acknowledgements}

This work was supported by the National Key Research and Development Program of China (Grant No. 2018YFD1100102).

\section{References}

1. ZHANG Yin, ZHANG Yin, MIN Jie. An analysis of coupling between the bearing capacity of the ecological environment and the quality of new urbanization in Chongqing[J]. Acta Geographica Sinica, 2016, 71 (5): 817- 828.

2. LIN Xueqin, WANG Dai. Spatiotemporal evolution of urban air quality and socioeconomic driving forces in China[J]. Acta Geographica Sinica, 2016, 26(11):1533-1549.

3. ZHOU Xuelan. Based on the study of "urban disease" in the process of urbanization in China[J]. Journal of Urban Geography, 2017.

4. Lian Jie. Study on the characteristics, variation rules and prediction of acoustic environment in typical urban areas[D]. University of Technology, 2013.

5. Laszlo H E, Mcrobie E S, Stansfeld S A, et al. Annoyance and other reaction measures to changes in noise exposure - A review $[\mathrm{J}]$. Science of the Total Environment, 2012, 435-436(7):551-562.

6. Montalvao Guedes AC, Bertoli SR, Zannin PHT. Influence of urban shapes on environmental noise: a case study in Aracaju-Brazil[J]. Science of the Total Environment, 2011, 412-413:66-76.

7. Lian Jie, Ma Mingtang, Liu Jie. The application of color theory and model in the study of acoustic environment in typical urban areas of Beijing $[\mathrm{J}]$. The Administration and Technique of Environmental Monitoring, 2013, 25(3):21-25.

8. He Qihuan. Environmental noise control engineering $[\mathrm{M}]$. Tsinghua University Press, 2011:2-3.

9. Saldanha A.2009. Soundscape//Kitchin R, Thrift N. International encyclopedia of human geography[Z]. Oxford, UK: Elsevier.

10. Liu Aili, Liu Fucheng, Deng Zhiyong, et al. Soundscape research and related progress from the perspective of cultural geography[J]. Progress in Geography, 2014, 33(11):1452-1461.

11. Gilbson C, Waitt G.2009. Cultural Geography//Kitchin R,Thrift N. International encyclopedia of human geography[Z]. Oxford, UK: Elsevie

12. Tardieu J , Susini P, Poisson F, et al. Perceptual study of soundscapes in train stations[J]. Applied Acoustics, 2015, 69(12):1224-1239.
13. Joo W, Gage S H, Kasten E P . Analysis and interpretation of variability in soundscapes along an urban-rural gradient[J]. Landscape and Urban Planning, 2011, 103(3-4):259-276.

14. Xue Yibin. Moving sound landscape -- a new approach of music geography[J]. Journal of Central Music College, 2008(1):83-88.

15. Liu Aili, $\mathrm{Hu}$ Zhongzhou, Liu Min, et al. Sonography and its application in the study of tourism geography $[\mathrm{J}]$. Geographical Research, 2013, 32(6):1132-1142.

16. Li Guoqi. Sound scene study and sound scene design [D]. Tsinghua University, 2004.

17. Wang Yi, Bao Zhiyi. Application and discussion of soundscape in landscape design[J]. Huazhong Architecture, 2007, 25(7):150-152.

18. Qin Hua, Sun Chunhong. Analysis of soundscape characteristics of urban parks [J]. Chinese Garden, 2009, 25(7):28-31.

19. Zhu huailiang, yuan erna, li peng, et al. Environmental noise measurement and analysis of urban three-dimensional rail transit[J]. Journal of Shanghai University (natural science edition), 2009, 15(6):611-614.

20. Wang deli. Reducing the impact of railway noise on residents' environment by using sound barrier[J]. Journal of Shenyang Normal University (natural science edition), 2007, 25(3):381-383.

21. Yang youliang, mecre yi.Abilitifu. Investigation and analysis of campus environmental noise in friendship campus of Northwestern Polytechnical University[J]. Noise Control, 2010, 34(1):82-85.

22. Cao guangzhong, gao xiaowen, liu tao. Characteristics of urban land use growth in metropolitan and non-metropolitan areas: a case study of the Yangtze river delta region[J]. Human Geography, 2011(5):65-70.

23. Ministry of environmental protection. Acoustic environmental quality standards[R]. 2008-10-01.

24. First, A new Line of City Institute of Finance and Economics. 2018 Chinese Urban Commercial Charm[OL].

https://www.yicai.com/news/5418765.html, 2018-04-26.

25. Chen jianrong, hu junjie, zhu dong. Research on $\operatorname{PM}(2.5)$ spatial distribution analysis system supported by WebGIS[J]. Geospatial Information, 2016, 14(1):46-48.

26. Yan junjie, liu haijun, cui dong, et al. Spatiotemporal variation characteristics of grassland degradation in yili valley, xinjiang in recent 15 years[J]. Pratacultural Science, 2018, 35(3):508-520.

27. Kang J , Zhang M . Semantic differential analysis of the soundscape in urban open public spaces[J]. Building \& Environment, 2010, 45(1):150-157.

28. Rychtáriková M, Vermeir G. Soundscape categorization on the basis of objective acoustical 
parameters[J]. Applied Acoustics, 2013, 74(2):240-247.

29. Scales R. Soundscapes of the Urban Past: Staged Sound as Mediated Cultural Heritage ed. by Karin Bijsterveld (review) $[\mathrm{J}]$. Historische Zeitschrift, 2014, 299(2):579-581.

30. Bijsterveld K. Soundscapes of the urban past: staged sound as mediated cultural heritage. Bielefeld, Germany:Transcript Verlag[Z]. 2013.

31. Chen shili, tao haiyan, li xuliang, et al. Identification of urban functional areas based on potential semantic information -- GPS spatiotemporal data mining of floating cars in guangzhou[J]. Acta Geographica Sinica, 2016, 71(3):471-483.

32. China environmental monitoring station. 2017 China environmental noise pollution prevention and control report[OL]. http://www.cnemc.cn/2017-11-08.

33. Xue junfei. Hierarchical structure and distribution pattern of urban system in China based on aviation network[J]. Geography Research, 2008, 27(1):23-3

34. Torija A J , Ruiz D P , Ángel Ramos-Ridao. Required stabilization time, short-term variability and impulsiveness of the sound pressure level to characterize the temporal composition of urban soundscapes[J]. Applied Acoustics, 2011, 72(2):89-99.

35. Zhang chi, liu maosong, $\mathrm{xu}$ chi, et al. Hotspot analysis of settlement dynamics during urbanization in nanjing city[J]. Chinese Journal of Ecology, 2009, 28(3):503-508. 